Research Article

\title{
A comprehensive transcriptome analysis of skeletal muscles in two Polish pig breeds differing in fat and meat quality traits
}

\author{
Katarzyna Piórkowska ${ }^{1}$ D , Kacper Żukowski ${ }^{3}$, Katarzyna Ropka-Molik ${ }^{1}$, Mirosław Tyra $^{2}$ and Artur Gurgul $^{1}$ \\ ${ }^{I}$ Department of Animal Molecular Biology, National Research Institute of Animal Production, Balice, \\ Poland. \\ ${ }^{2}$ Department of Pig Breeding, National Research Institute of Animal Production, Balice, Poland. \\ ${ }^{3}$ Department of Cattle Breeding, National Research Institute of Animal Production, Balice, Poland.
}

\begin{abstract}
Pork is the most popular meat in the world. Unfortunately, the selection pressure focused on high meat content led to a reduction in pork quality. The present study used RNA-seq technology to identify metabolic process genes related to pork quality traits and fat deposition. Differentially expressed genes (DEGs) were identified between pigs of Pulawska and Polish Landrace breeds for two the most important muscles (semimembranosus and longissimus dorsi). A total of 71 significant DEGs were reported: 15 for longissimus dorsi and 56 for semimembranosus muscles. The genes overexpressed in Pulawska pigs were involved in lipid metabolism (APOD, LXRA, LIPE, AP2B1, ENSSSCG00000028753 and OAS2) and proteolysis (CST6, CTSD, ISG15 and UCHL1). In Polish Landrace pigs, genes playing a role in biological adhesion (KIT, VCAN, HES1, SFRP2, CDH11, SSX2IP and PCDH17), actin cytoskeletal organisation (FRMD6, LIMK1, KIF23 and CNN1) and calcium ion binding (PVALB, CIB2, PCDH17, VCAN and $C D H 11$ ) were transcriptionally more active. The present study allows for better understanding of the physiological processes associated with lipid metabolism and muscle fiber organization. This information could be helpful in further research aiming to estimate the genetic markers.
\end{abstract}

Keywords: RNA-seq, firmness, fat content, Polish pigs.

Received: April 11, 2016; Accepted: September 11, 2017.

\section{Introduction}

Over the past few decades, meat content of pig carcasses has been significantly increased. The intention was to decrease backfat thickness, but unfortunately level of intramuscular fat (IMF) was also reduced. The breeding efforts were motivated by societal needs, especially in Poland, where a high meat yield was the aim. Today, Polish pigs have a thin backfat, low percentage of IMF and poor texture parameters, which influence an inferior flavour and low technological suitability (Tyra and Zak, 2013). The traditional breeding methods are expensive and time-consuming because they are based on an evaluation of adult pigs. Therefore, the development of genetic markers associated with the desired phenotype should indicate animals having breeding potential.

To date, several interesting discoveries are made in the field of gene polymorphisms affecting pork quality. When analyzing intramuscular fat (IMF), which is considered as the main factor determining the flavour of meat, it

Send correspondence to Katarzyna Piórkowska. Department of Animal Molecular Biology, National Research Institute of Animal Production, 32-083 Balice, Poland, E-mail: katarzyna.piorkowska@izoo.krakow.pl. was observed that mutations in $H-F A B P$, (Pang et al., 2006), LPL and LIPE genes (Xue et al., 2015) influenced IMF content. In turn, Zhang et al. (2014) evaluating the effect of 33 single nucleotide polymorphisms (SNPs) on pork quality traits showed that mutations in $A M P D 1, A D I P O Q$ and $C O P 1$ were associated with juiciness, and $F T O, T N F$, HSP70.2 and CAST were involved in pork color determination. The CAST gene encodes calpastatin, a key enzyme in the calpain system. In a study by Ropka-Molik et al. (2014a), it was established that CAST also affected meat texture parameters, such as firmness and toughness, as well as $\mathrm{pH}$ and water holding capacity (WHC).

Pork tenderness was considered by Miller et al. (2001) as the most important factor determining technological suitability. This parameter is associated with postmortem tenderisation, when the proteolysis process is activated in response to a reduction of $\mathrm{pH}$, including the calpain system responsible for the conversion of muscle to meat, the caspase cascade associated with apoptosis, and also cathepsin proteases produced by lysosomes (Huff- Lonergan et al., 2010). The genes encoding these proteins were considered as potential candidates for pork quality traits, but without spectacular discoveries. 
Currently, the estimation of genetic markers for farm animal quantitative traits represents a major challenge. In pigs, only several genes (RYR1, PRKAG3 and IGF2) with major phenotypic effect were identified. Because the quantitative traits are the result of the cooperation of many genes, capturing the function and interaction of the whole genome is necessary. A new evaluation method of dairy cattle, the genomic estimated breeding value (GEBV), was developed (Hayes et al., 2009). The method uses SNP microarray results as support for the traditional breeding evaluation.

On of the genomics methods, RNA-seq, is used to analyze transcriptome profiles. This method has been widely applied in recent years because the RNA-seq results are much more informative in comparison to the results obtained by gene expression microarray technology. The microarray technique is unable to detect new transcripts, gene translocation, inversion and alternative splice variants (Hurd and Nelson, 2009), whilst RNA-seq provides these opportunities. The major application of the RNA-seq method is an evaluation of differentially expressed genes (DEGs) between investigated groups. For example in pigs, the RNA-seq method was used to estimate the transcriptome profile depending on breed (Ropka-Molik et al., 2014b), type of tissue (Esteve-Codina et al., 2011) and phenotype (Corominas et al., 2013). The RNA-seq method also provides information on the transcript sequences, and therefore could be used for identification of gene mutations. Martínez-Montes et al. (2016) detected potential genetic markers for porcine growth and fat traits using RNA-seq.

In the present study, the comparison of muscle transcriptomic profiles between Pulawska (PUL) and Polish Landrace (PL) breeds was performed. The investigated pig groups showed highly significant differences in fat content of the carcass and in meat quality traits. PUL is one of the indigenous Polish breeds included in the genetic resources conservation programme (Szyndler-Nedza et al., 2010) that was not under selection pressure. Therefore, PUL pork characterizes with high meat quality, fat content, and is recognized as a delicacy on Polish tables (Kasprzyk et al., 2015). A few years ago, it was proposed to use the ham of these pigs as a dry-cured product (Olkiewicz, 2009). In numerous countries, indigenous pigs are maintained as a genetic diversity reservoir. They are usually characterized by high-fat content and very good reproduction performance, such as the Chinese Tongcheng pigs (Fan et al., 2006), and by low growth rate as in the Zimbabwe Mukota pigs (Chimonyo et al., 2010). The second investigated PL breed is used in Polish breeding as a maternal component. These pigs characterize with good reproductive performance, high meat content, and growth traits. Nevertheless, as a result of the breeding efforts, PL pork is not as tasty, due to high drip loss and low IMF content (Tyra and Zak, 2013). PL shows high similarity to other white pigs maintained in
Europe, because it originated from the Swedish Landrace and the German Large White.

Consequently, the present study has attempted to identify genes involved in the determination of pork traits, including the regulation of fat metabolism, meat quality and growth performance.

\section{Material and Methods}

\section{Animals}

The study was conducted on 16 gilts of PUL $(n=8)$ and PL $(n=8)$. The animals were maintained at the Pig Testing Station of the National Research Institute of Animal Production in Chorzelów under the same housing and feeding conditions. The pigs came from different farms and were unrelated. They were delivered to the test station as piglets and fed ad libitum from 30 up to $100( \pm 2.5) \mathrm{kg}$ of body weight, after which they were starved for $24 \mathrm{~h}$ before slaughter. Stunning with high-voltage electric tongs was followed by exsanguination. After chilling for $24 \mathrm{~h}$ at $4{ }^{\circ} \mathrm{C}$, the right half-carcass was evaluated. Carcass traits were measured according to Tyra and Zak (2013). Meat texture parameters and $\mathrm{pH}$ for the longissimus dorsi (LD) and semimembranosus (S) muscles were determined according to Ropka-Molik et al. (2014a). The meat exudation, IMF and meat colour were measured in longissimus dorsi. The meat exudation was determined as the amount of free water according to the filter paper press method of Grau and Hamm (1953) as the ratio between pressed water (meat exudate) to total water content, where $1 \mathrm{~cm}^{2}$ of expressed juice ring after pressing corresponds to $10 \mathrm{mg}$ of water loss, and total water content is $75 \%$ of the total meat weight (Huff-Lonergan and Lonergan, 2005). IMF and meat color were measured as described by Tyra et al. (2013). Muscle samples for molecular analysis were collected immediately (up to $20 \mathrm{~min}$ ) after slaughter, stabilized in RNAlater solution (Ambion) and stored at $-20^{\circ} \mathrm{C}$.

\section{NGS library construction}

RNA was isolated using TRI Reagent (Applied Biosystems) according to the manufacturer's protocol. Muscle samples were homogenized using a Bullet Blender 24 homogenizer (Next Advance). The RNA (Agencourt RNAClean XP kit) was purified by a bead method and its quality and quantity were assessed fluoremetrically (Qubit Fluorometer, Invitrogen) and by the TapeStation 2200 system (RNA tapes, Agilent). RNA integrity number (RIN) was in the range between 6.8-8. Ribosomal RNA from $5000 \mathrm{ng}$ of total RNA was removed using a Ribo-Zero Gold rRNA Removal Kit (Human/Mouse/Rat) (Epicentre). The absence of rRNA was verified on the TapeStation 2200 system. The elimination of rRNA leads to a flattening of the differences in transcript levels between the groups and allows for sequencing of cDNA libraries presenting low frequency (Benes et al., 2011). A TruSeq RNA Sample 
Preparation Kit v2 (Illumina) was used to prepare cDNA libraries from $100 \mathrm{ng}$ aliquots of rRNA-depleted samples according to the manufacturer's protocol. The cDNA samples were ligated with indexed adaptors in the order shown in Table S1. The libraries were amplified in 15 cycles of PCR, and their quantity was estimated using the Qubit 2.0 Fluorometer and 2200 TapeStation (D1000 tapes). The final concentration of the cDNA libraries was normalized to 10 $\mathrm{nM}$, after which the libraries were pooled (Table S1).

\section{Whole genome sequencing}

The libraries were diluted according to a cluster generation protocol and loaded into a v3 Illumina Flowcell (16 samples per line with four technical replicates; the technical replicates were used to avoid the lane effect). Single-read clusters were generated on a cBot system (Illumina). Flowcell clustering was performed using TruSeq SR Cluster Kit v3-cBot- 4 HS. Sequencing-bysynthesis of the clustered libraries was conducted on a HiScanSQ System in 81 bp single-end cycles using TruSeq SBS Kit v3-HS chemistry (Illumina).

\section{Raw reads processing}

The raw sequences were qualitatively controled using the FastQC tool. Next, Flexbar software was used to remove Illumina adapters, poly-A sequences and reads shorter than $36 \mathrm{bp}$ or with a quality score $<20$. Filtered sequences were aligned to the Sus scrofa genome (Sscrofa10.2 assembly) with reference annotation containing the 21,630 genes listed in the Ensembl database. Alignment and estimation of the gene expression levels were performed using the RSEM package supported by Bowtie 2 aligner. The alignment and DEG statistics were generated using the Picard tools (http://picard. sourceforge.net and RNA-SeQC tools). The sequence data were submitted to Gene Expression Omnibus (accession no. GSE75707, https://www.ncbi.nlm.nih.gov/geo/query/acc.cgi?acc=GS E75707).

\section{DEG analysis}

The DEG analysis was performed using edgeR (Robinson and Oshlack, 2010), baySeq (Hardcastle and Kelly, 2010) and DESeq2 (Love et al., 2014) separately for each muscle and breed, which was preceded by PCA (DESeq2) and MDS (edgeR) analyses. The significance for particular methods was presented as false recovery rate (FDR) by edgeR and baySeq, and as adjusted $P$-values by DESeq 2 . Transcripts with a fold change $\geq 1.30$ and evaluated by at least two methods as significant $(P \leq 0.05)$, were included in the further analysis. Functional analysis of DEGs was performed by Panther Gene List software, where the $P$-value was estimated in overrepresentation tests and Kobas 3.0, which predicts biological pathways based on the KEGG, Reactome and Biocyc databases.

\section{Gene panel validation by qPCR}

Seventeen differentially expressed genes were selected for qPCR validation: CNN1, PVALB, HP, OAS1, LXRA, APOD, LIMK1, PEX11G, UCHL1, MAOB, ASS1, GPX3, VCAN, SFRP2, HES1, PPPIR11, LIPE. Primers and probes for the investigated genes were purchased from Applied Biosystems as TaqMan Assays (Applied Biosystems), or primers for some genes were designed in Primer3 and synthesized by Genomed (Poland). The primers and assays used in the validation were presented in Table S2. cDNA was prepared from 1,000 ng of total RNA by using TRANSCRIPTME Reverse Transcriptase (DNA Gdansk). TaqMan ${ }^{\circledR}$ Gene Expression Master Mix (Applied Biosystem) and AmpliQ 5x Hot EvaGreen (Novazym) were used to perform analyses on a 7500 RealTime PCR System (Applied Biosystems). Each qPCR analysis was performed with three replicates. Mean CT values were obtained with an acceptable error of 0.3 . Relative mRNA abundance (RQ) was measured by the $\triangle \Delta \mathrm{CT}$ method. As an endogenous control, two genes, $O A Z 1$ and $R P L 27$, were used. These are known as being stable in regard to the expression in muscle tissue. The $\mathrm{M}$ values describing the stability of endogenous control genes were estimated for $O A Z 1$ and $R P L 27$ by geNorm, and they were under 0.5. The comparison between RNA-seq and qPCR results was performed using Pearson's correlation analysis, and significant differences in gene expression (qPCR) between analyzed groups were estimated using ANOVA with post-hoc Duncan test (SAS Enterprise).

\section{Correlation analysis}

Seventeen validated genes were included in the Pearson's correlation (SAS Enterprise) analysis for important growth, carcass and meat quality traits with $P$-value thresholds: ${ }^{*} P \leq 0.05, * * P \leq 0.01, * * * P \leq 0.001$, and also the Bonferroni corrected P-value. The comparison between porcine traits and FPKM was performed for each muscle separately. For the most interesting association, regression plots were created.

\section{Results}

\section{Animal characteristics}

In the present study, 16 gilts of two pig breeds were evaluated in regard to carcass and meat quality parameters. The PUL backfat was thicker by $40 \%(P<0.05)$. In turn, the investigated PL pigs were characterized by higher ham mass, daily gain by $210 \mathrm{~g}(P<0.01)$, meat percentage and better feed conversion $(P<0.01)$. Moreover, as was expected, PL pork was less tender and had higher water exudation than that of PUL pigs (Table 1), which was observed for both analyzed muscles. 
Table 1 - Characteristics of the pig, breeds, means \pm SD.

\begin{tabular}{|c|c|c|c|c|}
\hline \multirow[t]{2}{*}{ Traits } & \multicolumn{2}{|c|}{ PL $(n=8)$} & \multicolumn{2}{|c|}{ PUL $(n=8)$} \\
\hline & Mean & $\mathrm{SD}$ & Mean & $\mathrm{SD}$ \\
\hline Daily gain (g) & $972^{\mathrm{A}}$ & 86.6 & $763^{\mathrm{B}}$ & 48.2 \\
\hline Feed conversion $(\mathrm{kg} / \mathrm{kg})$ & $2.60^{\mathrm{A}}$ & 0.08 & $2.96^{\mathrm{B}}$ & 0.14 \\
\hline Carcass yield \% & 76.24 & 2.27 & 75.64 & 3.98 \\
\hline Weight of loin $(\mathrm{kg})$ & 6.19 & 0.57 & 5.65 & 0.50 \\
\hline Weight of ham $(\mathrm{kg})$ & $9.31^{\mathrm{a}}$ & 0.26 & $8.63^{b}$ & 0.74 \\
\hline Backfat thickness $(\mathrm{cm})$ & $1.18^{\mathrm{a}}$ & 0.17 & $1.64^{\mathrm{b}}$ & 0.40 \\
\hline Loin eye area $\left(\mathrm{cm}^{2}\right)$ & 52.50 & 5.25 & 48.94 & 5.18 \\
\hline Meat percentage $\%$ & $63.04^{\mathrm{a}}$ & 1.95 & $59.5^{b}$ & 2.80 \\
\hline \multicolumn{5}{|l|}{ Longissimus dorsi muscle } \\
\hline Meat exudation & $41.50^{\mathrm{A}}$ & 5.11 & $28.32^{\mathrm{B}}$ & 1.24 \\
\hline \multicolumn{5}{|l|}{ Meat color } \\
\hline Meat lightness & 55.08 & 2.21 & 53.72 & 1.74 \\
\hline Meat redness & 16.70 & 1.19 & 16.16 & 0.81 \\
\hline Meat yellowness & 2.16 & 0.99 & 2.25 & 0.62 \\
\hline Intramuscular fat & 1.08 & 0.21 & 1.19 & 0.12 \\
\hline pH45 & 6.33 & 0.18 & 6.32 & 0.19 \\
\hline $\mathrm{pH} 24$ & 5.63 & 0.05 & 5.60 & 0.06 \\
\hline Firmness by WB (cooked meat) & $122.58^{\mathrm{A}}$ & 14.7 & $57.7^{\mathrm{B}}$ & 3.21 \\
\hline Toughness by WB (cooked meat) & $277.07^{\mathrm{A}}$ & 37.6 & $140.97^{\mathrm{B}}$ & 14.2 \\
\hline Harness by TPA (cooked loin) & 6.95 & 2.7 & 5.01 & 2.05 \\
\hline \multicolumn{5}{|l|}{ Semimembranosus muscle } \\
\hline Firmness by WB (cooked meat) & $89.92^{\mathrm{a}}$ & 10.17 & $75.13^{\mathrm{b}}$ & 6.83 \\
\hline Toughness by WB (cooked meat) & 203.91 & 39.72 & 180.30 & 35.86 \\
\hline Harness by TPA (cooked meat) & 9.30 & 3.84 & 8.25 & 3.88 \\
\hline
\end{tabular}

Abbreviation: SD- standard deviation, TPA-texture parameter analysis, WB- Warner-Bratzler, PL- Polish Landrace, PUL- Pulawska. Values with the same superscripts show significant differences between genotypes $(\mathrm{A}, \mathrm{B}=P<0.01 . \mathrm{a}, \mathrm{b}=P<0.05)$

\section{Transcriptome analysis}

The average number of raw reads detected per sample was $23,633,127$, and after filtration it was $23,453,870$. After mapping to the pig reference genome (Sscrofa10.2 assembly) (Table S1), $63.15 \%$ of the reads matched annotated exon regions, and $7.83 \%$ matched introns. The comparison of transcriptome profiles between the analyzed breeds showed that in the PUL longissimus dorsi (LD) muscle, six overexpressed genes were detected, and in semimembranosus (S), 28 genes showed increased expression (Tables 2 and S3). Among these up-regulated genes, there are some engaged in lipid metabolism (ENSSSCG00000028753, LIPE, LXRA, APOD, GPX3 and $A P 2 B 1$ ), actin filament building (LIMK1), proteolysis (CTSD, CST6, UCHL1, ISG15, LXRA), and carbohydrate derivative binding (KHK, SEPT6, LIMK1, ASS1, HP, $O A S 2$ ) (Tables 3 and 4). In turn, genes overexpressed in PL muscles are involved in several biological processes, such as cell adhesion (KIT, VCAN, HES1, SFRP2, CDH11, SSX2IP, PCDH17), calcium ion binding (PVALB, CIB2, $P C D H 17, V C A N$ and $C D H 11$ ), and actin organisation (CNN1, FRMD6, KIF23) (Tables 3 and 4). The differentially expressed isoform analysis showed that in both muscles of PUL the seventh isoform of the SEPT6 gene showed increased expression. This isoform is composed of 10 exons, which encode all three important protein domains.

\section{qPCR results}

Validation by qPCR is commonly used to confirm RNA-seq results (Piórkowska et al., 2016, Ropka-Molik et al., 2014b), and this was done here for 17 differentially expressed genes. The comparison between RNA-seq and qPCR results was performed by Pearson's correlation test. The lowest result was observed for the LIPE gene ( $r=0.57$, $P \leq 0.05)$. Figure 1 presents the fold change of expression levels for the most important genes. Genes encoding proteins associated with lipid homeostasis were overexpressed 


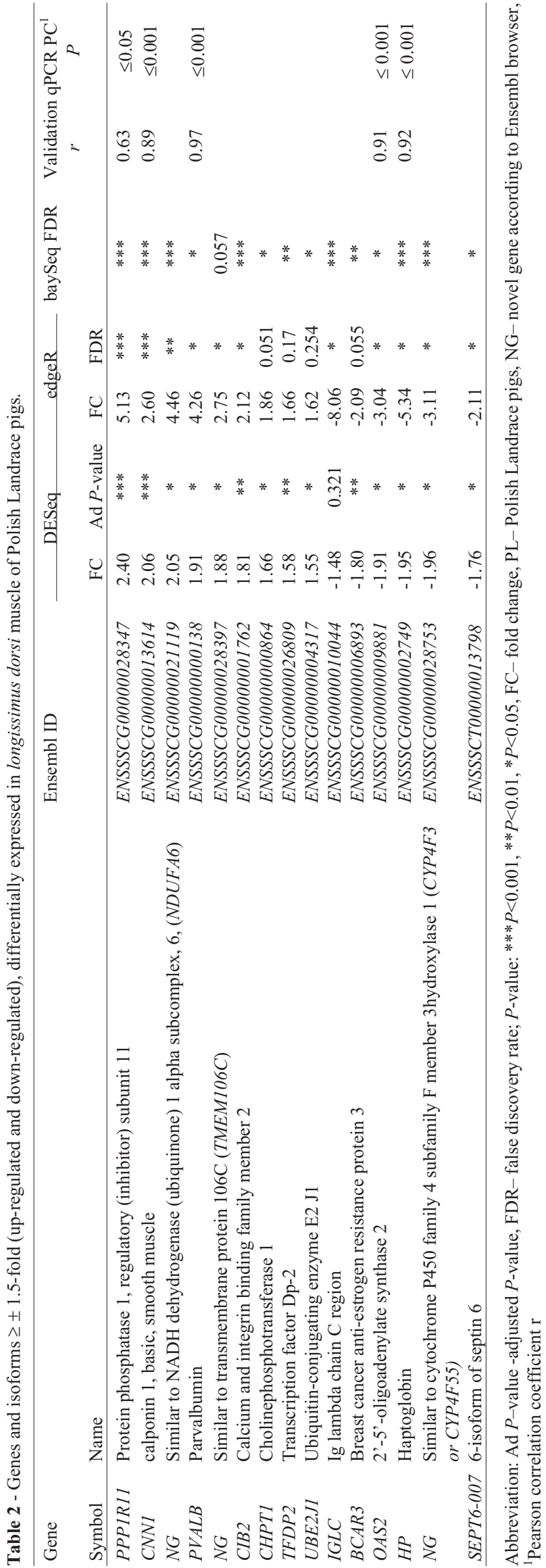

in PUL muscle (Table 3), while those involved in cell adhesion, such as VCAN and HES1 (Table 4), showed higher transcript levels in PL muscle. The fold change of gene expression values between PUL and PL for RNA-seq (FPKM) and qPCR (RQ of mRNA) results are uploaded for consultation at goo.gl/eaXXcO.

\section{Correlation of gene expression and pig traits}

The correlation analysis between porcine phenotypic traits and FPKM values revealed many interesting results. PPP11R1 and CNN1 expressions in longissimus dorsi were positively correlated with daily gains $(r=0.80$, corrected $P<0.01$ and $r=0.68$, corrected $P<0.05$, respectively). In turn, $M A O B$ expression in both muscles was positively associated with feed intake (LD $r=0.66$, corrected $P<0.05$ and $\mathrm{S} r=0.66$, corrected $P<0.05)$. Furthermore, LIMK1 expression in semimembranosus was negatively related to meat percentage $(r=-0.68$, corrected $P<0.05)$, and highly positive correlation results between PPP11R1, PVALB, CNN1 expressions in LD and meat texture parameters were obtained. The expression of UCHL1 in LD muscle showed a negative association with water exudation (Tables S4 and S5, Figure 2).

\section{Discussion}

The breeding strategy that has been focused on lean pork led to a reduction of IMF percentage and meat tenderness. Therefore, searching for genetic markers for these traits seems a promising strategy. The new possibilities using innovative molecular techniques enable to indicate physiological processes involved in the shaping of farm animal traits. The present study attempted to identify genes and metabolic pathways that may influence meat quality and fat traits in pigs.

\section{Genes overexpressed in Pulawska pigs}

Because the PUL breed has not been under selection pressure focused on high meat content in the carcass, the PUL pigs used in the present study were characterized by high backfat mass and pork quality, including good meat texture parameters and low water exudation. As in the other indigenous breeds, the PUL showed poor growth traits included daily gain (200 g lower than PL), feed conversion $(0.3 \mathrm{~kg} / \mathrm{kg}$ higher than PL) and low mass of the most important carcass cuts.

The transcriptomic analysis of PUL muscles showed that genes associated with fat content and lipid metabolism revealed increased expression (LIPE, APOD, LXRA, ENSSSCG00000028753, AP2B1, GPX3 and ASS1). The LIPE gene, which encodes a hormone-sensitive lipase, plays a role in triacylglycerol biosynthesis. The main function of LIPE is to mobilize stored fats by hydrolyzing the first fatty acid from a triacylglycerol molecule (Holm et al., 1994). The LIPE gene was previously analyzed regarding fatty acid composition in pigs. Xue et al. (2015) showed 
Table 3 - Functional annotation of differentially expressed genes in longissimus dorsi muscle of pigs.

\begin{tabular}{|c|c|c|c|c|}
\hline \multirow[t]{2}{*}{ Gene ontology } & \multicolumn{4}{|c|}{ Genes } \\
\hline & $P$-value & $\begin{array}{c}\text { Corrected } \\
\text { P-value }\end{array}$ & up-regulated in Pulawska pigs & $\begin{array}{l}\text { up-regulated in Polish } \\
\text { Landrace }\end{array}$ \\
\hline GO:0072562 blood microparticle & $1.62 \mathrm{E}-05$ & $1.20 \mathrm{E}-02$ & $H P, I G L C$ & $C I B 2$ \\
\hline GO:0032515 negative regulation of catabolic process & $1.61 \mathrm{E}-03$ & $1.16 \mathrm{E}-01$ & $H P$ & $U B E 2 J 1$ \\
\hline GO:0018377 protein myristoylation & $2.62 \mathrm{E}-03$ & $1.16 \mathrm{E}-01$ & $O A S 2$ & \\
\hline GO:1901568 fatty acid derivative metabolic process & $4.80 \mathrm{E}-03$ & $1.16 \mathrm{E}-01$ & ENSSSCG00000028753 & \\
\hline GO:0019992 diacylglycerol binding & $5.24 \mathrm{E}-03$ & $1.16 \mathrm{E}-01$ & & CHPT1 \\
\hline GO:0051480 regulation of cytosolic calcium ion concentration & $5.90 \mathrm{E}-03$ & $1.16 \mathrm{E}-01$ & & $C I B 2, P V A L B$ \\
\hline GO:0009056 catabolic process & $6.99 \mathrm{E}-03$ & $1.16 \mathrm{E}-01$ & $\begin{array}{l}\text { HP, ENSSSCG00000028753, } \\
\text { OAS2 }\end{array}$ & $U B E 2 J 1$ \\
\hline GO:0009101 glycoprotein biosynthetic process & $9.32 \mathrm{E}-03$ & $1.20 \mathrm{E}-01$ & & $C I B 2$ \\
\hline GO:0005924 cell-substrate adherens junction & $3.11 \mathrm{E}-03$ & $1.21 \mathrm{E}-01$ & & $C I B 2, C N N 1$ \\
\hline GO:0061631 ubiquitin conjugating enzyme activity & $1.26 \mathrm{E}-02$ & $1.21 \mathrm{E}-01$ & & $U B E 2 J 1$ \\
\hline GO:0031594 neuromuscular junction & $7.89 \mathrm{E}-03$ & $1.21 \mathrm{E}-01$ & & $C I B 2$ \\
\hline GO:0042158 lipoprotein biosynthetic process & $3.83 \mathrm{E}-02$ & $1.48 \mathrm{E}-01$ & OAS2 & \\
\hline GO:0033559 unsaturated fatty acid metabolic process & $4.58 \mathrm{E}-02$ & $1.48 \mathrm{E}-01$ & ENSSSCG00000028753 & \\
\hline GO:0005178 integrin binding & $1.73 \mathrm{E}-02$ & $1.24 \mathrm{E}-01$ & & $U B E 2 J 1$ \\
\hline GO:0042758 long-chain fatty acid catabolic process & 3.67E-03 & $1.48 \mathrm{E}-01$ & ENSSSCG00000028753 & \\
\hline GO:0005509 calcium ion binding & $9.71 \mathrm{E}-03$ & $1.21 \mathrm{E}-01$ & ENSSSCG00000028753 & \\
\hline GO:0042383 sarcolemma & $1.65 \mathrm{E}-02$ & $1.24 \mathrm{E}-01$ & & $C I B 2$ \\
\hline GO:0031032 actomyosin structure organization & $2.43 \mathrm{E}-02$ & $1.24 \mathrm{E}-01$ & & $C N N 1$ \\
\hline \multicolumn{5}{|l|}{ Pathway } \\
\hline R-SSC-1483206 glycerophospholipid biosynthesis & 4.75E-02 & $1.50 \mathrm{E}-01$ & & CHPT1 \\
\hline PWY3O-450 phosphatidylcholine biosynthesis & $3.06 \mathrm{E}-03$ & $1.16 \mathrm{E}-01$ & & CHPT1 \\
\hline R-SSC-211935 fatty acids & $6.98 \mathrm{E}-03$ & $1.16 \mathrm{E}-01$ & ENSSSCG00000028753 & \\
\hline R-SSC-2142753 arachidonic acid metabolism & $2.42 \mathrm{E}-02$ & $1.34 \mathrm{E}-01$ & ENSSSCG00000028753 & \\
\hline R-SSC-556833 metabolism of lipids and lipoproteins & $3.78 \mathrm{E}-02$ & $1.48 \mathrm{E}-01$ & ENSSSCG00000028753 & CHPT1 \\
\hline PWY-7511 protein ubiquitylation & $1.82 \mathrm{E}-02$ & $1.27 \mathrm{E}-01$ & & $U B E 2 J 1$ \\
\hline ssc00565 ether lipid metabolism & $2.70 \mathrm{E}-02$ & $1.29 \mathrm{E}-01$ & & CHPT1 \\
\hline
\end{tabular}

GO-gene ontology and pathways were estimated by Kobas 3.0 and Panther Gene List

that LIPE (HSL) c.442 $\mathrm{G}>\mathrm{A}$ polymorphism affected the content of $\mathrm{C} 12: 0$ and $\mathrm{C} 14: 0$ fatty acids $(P<0.05)$. The correlation analysis carried out in the present study identified trends indicating that $L I P E$ expression in the longissimus dorsi muscle is positively related to IMF and backfat thickness values (but after Bonferroni correction the results were not significant). These findings should stimulate the search for genetic markers for fat content in the LIPE gene, which could be a good direction for further research.

The APOD and LXRA (NRIH3) genes encode proteins involved in the LXR/RXR activation pathway, and both have the ability to bind cholesterol. APOD promotes the conversion of HDL to LDL. Desai et al. (2002) found in Africans a few missense mutations, Phe36Val, Tyr108Cys and Thr158Lys, that were associated with elevated triglyceride levels and reduced HDL-cholesterol in plasma. Whereas, LXRA plays a role in lipid homeostasis by regulating the expression of genes involved in controling feed intake and cholesterol efflux (Christoffolete et al., 2010). In pigs, Yu et al. (2006) identified that LXRA HpyCH4III polymorphism was significantly associated with the total lipid content of Berkshire and Yorkshire carcasses.

In turn, the ENSSSCG00000028753 (CYP4F2 ortholog), GPX3 and ASS1 genes were described by Ponsuksili et al. (2011) as having an effect on the 'fat area' in pigs. Glutathione peroxidase 3 (GPX3) containing a selenocysteine residue at its active site protects the cell from oxidative damage by the reduction of lipid peroxides (Takahashi et al., 1987). A previous study showed that GPX3 levels in plasma were highly correlated with the triacylglycerides/HDL-cholesterol index and body mass in humans (Baez-Duarte et al., 2012). In the present study, pigs showing higher GPX3 expression in semimembranosus muscle have remained longer in the test conducted by Pig Station, which meant that they took more time to reach the weight of $100 \mathrm{~kg}$ (correlation with slaugh- 
Table 4 - Functional annotation of differentially expressed genes in semimembranosus muscle of pigs.

\begin{tabular}{|c|c|c|c|c|}
\hline \multirow[t]{2}{*}{ Gene ontology } & \multirow[t]{2}{*}{$P$-value } & \multirow{2}{*}{$\begin{array}{c}\text { Corrected } \\
P \text {-value }\end{array}$} & \multicolumn{2}{|c|}{ Genes } \\
\hline & & & up-regulated in Pulawska & up-regulated in Polish Landrace \\
\hline \multicolumn{5}{|l|}{ Gene ontology } \\
\hline GO:0007018 microtubule-based movement & $8.43 \mathrm{E}-06$ & 4.23E-03 & $A P 2 B 1, U C H L 1$ & TTC21B, DNAH11, KIF23, SSX2IP \\
\hline $\begin{array}{l}\text { GO:0032989 cellular component } \\
\text { morphogenesis }\end{array}$ & $1.21 \mathrm{E}-05$ & $4.81 \mathrm{E}-03$ & LIMK1, UCHL1, & $\begin{array}{l}\text { ENSSSCG00000016843, HES1, } \\
\text { SFRP2, TTC21B, FRMD6, TCHP, } \\
\text { CDH11, NR4A2, SSX2IP }\end{array}$ \\
\hline GO:0009056 catabolic process & $3.62 \mathrm{E}-05$ & $7.78 \mathrm{E}-03$ & $\begin{array}{l}C T S D, R G P 1, H S L, U C H L 1, H P \\
G P X 3, O A S 2, M A O B, K H K, I S G 15\end{array}$ & $\begin{array}{l}\text { COL11A1, ALDH1L2, VCAN, } \\
\text { HECTD2 }\end{array}$ \\
\hline $\begin{array}{l}\text { GO:0030705 cytoskeleton-dependent } \\
\text { intracellular transport }\end{array}$ & $1.51 \mathrm{E}-04$ & $1.45 \mathrm{E}-02$ & UCHL1 & TTC21B, KIF23, SSX2IP \\
\hline GO:0048565 digestive tract development & $2.54 \mathrm{E}-04$ & $2.06 \mathrm{E}-02$ & $A S S 1$ & KIT, HES1, SFRP2 \\
\hline GO:0097367 carbohydrate derivative binding & $6.08 \mathrm{E}-04$ & $3.46 \mathrm{E}-02$ & $\begin{array}{l}\text { SEPT6, LIMK1, ASS1, KHK, HP, } \\
\text { OAS2 }\end{array}$ & $\begin{array}{l}\text { KIT, VCAN, CHEK1, DNAH11, } \\
\text { KIF23, HELQ, NRK }\end{array}$ \\
\hline GO:0007155 cell adhesion & $3.18 \mathrm{E}-03$ & $6.50 \mathrm{E}-02$ & $A S S 1, A P O D$ & $\begin{array}{l}\text { KIT, VCAN, HES1, SFRP2, } \\
C D H 11, S S X 2 I P, P C D H 17\end{array}$ \\
\hline GO:0015485 cholesterol binding & $3.18 \mathrm{E}-03$ & $6.50 \mathrm{E}-02$ & $A P O D, L X R A$ & \\
\hline GO:0030199 collagen fibril organization & $3.34 \mathrm{E}-03$ & $6.50 \mathrm{E}-02$ & & COL11A1, SFRP2 \\
\hline GO:0006508 proteolysis & $1.81 \mathrm{E}-02$ & $1.14 \mathrm{E}-01$ & $\begin{array}{l}\text { CST6, CTSD, LXRA, ISG15, } \\
\text { UCHL1, HP }\end{array}$ & LXN, SFRP2, HECTD2 \\
\hline GO:0045444 fat cell differentiation & $9.75 \mathrm{E}-03$ & $1.14 \mathrm{E}-01$ & & NR4A2, HES1, SFRP2 \\
\hline $\begin{array}{l}\text { GO: } 0048638 \text { regulation of developmental } \\
\text { growth }\end{array}$ & $2.48 \mathrm{E}-02$ & $1.26 \mathrm{E}-01$ & LIMK1, RNPEPL1 & $N R K$ \\
\hline GO:0034332 adherens junction organization & $2.66 \mathrm{E}-02$ & $1.26 \mathrm{E}-01$ & $A P O D$ & $\mathrm{CDH} 11$ \\
\hline $\begin{array}{l}\text { GO: } 0031397 \text { negative regulation of protein } \\
\text { ubiquitination }\end{array}$ & $3.22 \mathrm{E}-02$ & $1.32 \mathrm{E}-01$ & LIMK1, ISG15 & \\
\hline GO:0032496 response to lipopolysaccharide & $3.31 \mathrm{E}-02$ & $1.32 \mathrm{E}-01$ & $M A O B, L X R A, A S S 1$ & \\
\hline GO:0042692 muscle cell differentiation & $3.74 \mathrm{E}-02$ & $1.32 \mathrm{E}-01$ & UCHL1 & KIT, HES1, SFRP2 \\
\hline GO:0005509 calcium ion binding & 4.13E-02 & $1.76 \mathrm{E}-01$ & & PCDH17, VCAN, CDH11 \\
\hline GO:0030036 actin cytoskeleton organization & 4.51E-02 & $2.39 \mathrm{E}-01$ & LIMK1 & FRMD6, KIF23 \\
\hline \multicolumn{5}{|l|}{ Pathway } \\
\hline $\begin{array}{l}\text { R-SSC-8866427 VLDLR internalization and } \\
\text { degradation }\end{array}$ & 4.04E-03 & 2.64E-02 & $L X R A, A P 2 B 1$ & \\
\hline ssc04390 hippo signaling pathway & 4.13E-03 & $3.29 \mathrm{E}-02$ & & PPP1R11, FRMD6 \\
\hline $\begin{array}{l}\text { R-SSC-73923 lipid digestion, mobilization, and } \\
\text { transport }\end{array}$ & $1.42 \mathrm{E}-03$ & 4.43E-02 & $H S L, L X R A, A P 2 B 1$ & \\
\hline R-SSC-174824 lipoprotein metabolism & $7.15 \mathrm{E}-03$ & $1.05 \mathrm{E}-01$ & $L X R A, A P 2 B 1$ & \\
\hline R-SSC-1442490 collagen degradation & $8.88 \mathrm{E}-03$ & $1.14 \mathrm{E}-01$ & $C T S D$ & COL11A1 \\
\hline R-SSC-804914 transport of fatty acids & $1.91 \mathrm{E}-02$ & $1.16 \mathrm{E}-01$ & $A P O D$ & \\
\hline ssc04910 insulin signaling pathway & $3.78 \mathrm{E}-02$ & 1.37E-01 & EXOC7, HSL & \\
\hline ssc00590 arachidonic acid metabolism & $3.56 \mathrm{E}-02$ & $1.37 \mathrm{E}-01$ & $G P X 3$ & \\
\hline $\begin{array}{l}\text { R-SSC-5627117 Rho GTPases Activate } \\
\text { ROCKs }\end{array}$ & $3.79 \mathrm{E}-02$ & 1.37E-01 & LIMK1 & \\
\hline
\end{tabular}

Functional analysis performed in Kobas 3.0 and Panther Gene List

ter age, $r=0.76$, corrected $P$-value $<0.01)$. This suggests that genes associated with lipid deposition are negatively correlated with pig weight gains. In turn, $C Y P 4 F 2$ encodes the leukotriene- $\mathrm{B}(4)$ omega-hydroxylase 1 protein, which is a member of the cytochrome 450 superfamily. This hydrolase plays a role in the conversion of arachidonic acid to 20-hydroxyeicosatetraenoic acid (20-HETE), and thereby, CYP4F2 reduces the fatty acid metabolite content and also is a preventing factor of lipotoxicity in fatty liver disease by regulation of the fatty acid metabolism (Hardwick et al., 2010). The above observations indicate a similar regulation involved in fat deposition and the appetite and satiety processes both in humans and pigs. This confirms the theory that pig is suitable for modeling of met- 


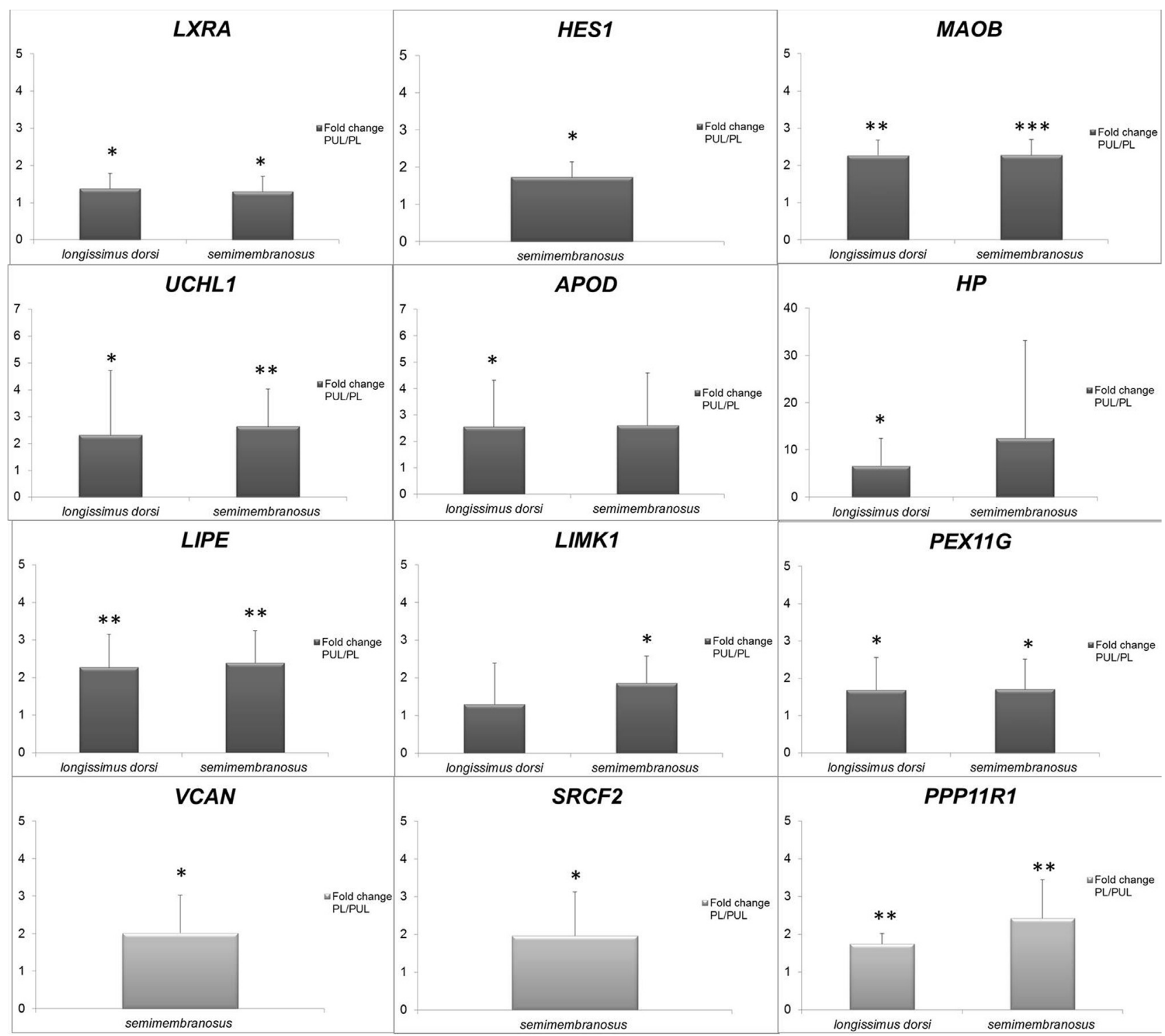

Figure 1 - Relative quantity of mRNA shown as fold change values between analyzed pig muscles (semimembranosus and longissimus dorsi). The brighter bars show FC values based on the PL pig group as reference and the darker bars show FC values with PUL as reference. The genes of interest were normalized by two endogenous control genes, $O A Z 1$ and $R P L 27$. ${ }^{*} P \leq 0.05,{ }^{* *} P \leq 0.01,{ }^{* * *} P \leq 0.001$.

abolic processes associated with human obesity, as previously suggested by Spurlock and Gabler (2008).

On the other hand, the PUL pigs used in the present study showed good meat tenderness and low water exudation. The RNA-seq analysis showed that in PUL muscles, genes (CST6, CTSD, ISG15, UCHL1 and HP) involved in proteolysis process were overexpressed. The correlation analysis revealed that UCHL1 expression in the longissimus dorsi muscle was negatively related to meat exudation $(r=-0.66$, corrected $P<0.05)$. The UCHL1 gene encodes ubiquitin $\mathrm{C}$-terminal hydrolase $\mathrm{L} 1$ that hydrolyzes a peptide bond at the $\mathrm{C}$-terminal glycine of ubiquitin. In the mouse model, it was observed that elevation of UCHL1 in fibroblasts was associated with spinal muscular atrophy (Hsu et al., 2010). However, the literature did not provide any information about the function of UCHL1 in muscle. The HP gene encodes haptoglobin, which is a circulating acute-phase protein having an anti-oxidant function. In humans, $H P$ expression is induced in white adipose tissue, which is reflected in the increased plasma levels of the glycoprotein found in obese subjects (Chiellini et al., 2004). In the present study, it was observed that $H P$ expression in the semimembranosus was negatively correlated with $\mathrm{pH}$ estimated $24 \mathrm{~h}$ after slaughter (corrected $P<0.05$ ). Thus, it could be closely related to the proteolysis process, which is activated post mortem in response to a decrease in $\mathrm{pH}$, which then determines meat tenderness (Huff-Lonergan et al., 2010). However, no significant correlation of $H P$ expression and meat texture parameters was observed in this study. The HP and UCHL1 functions are 
Longissimus dorsi
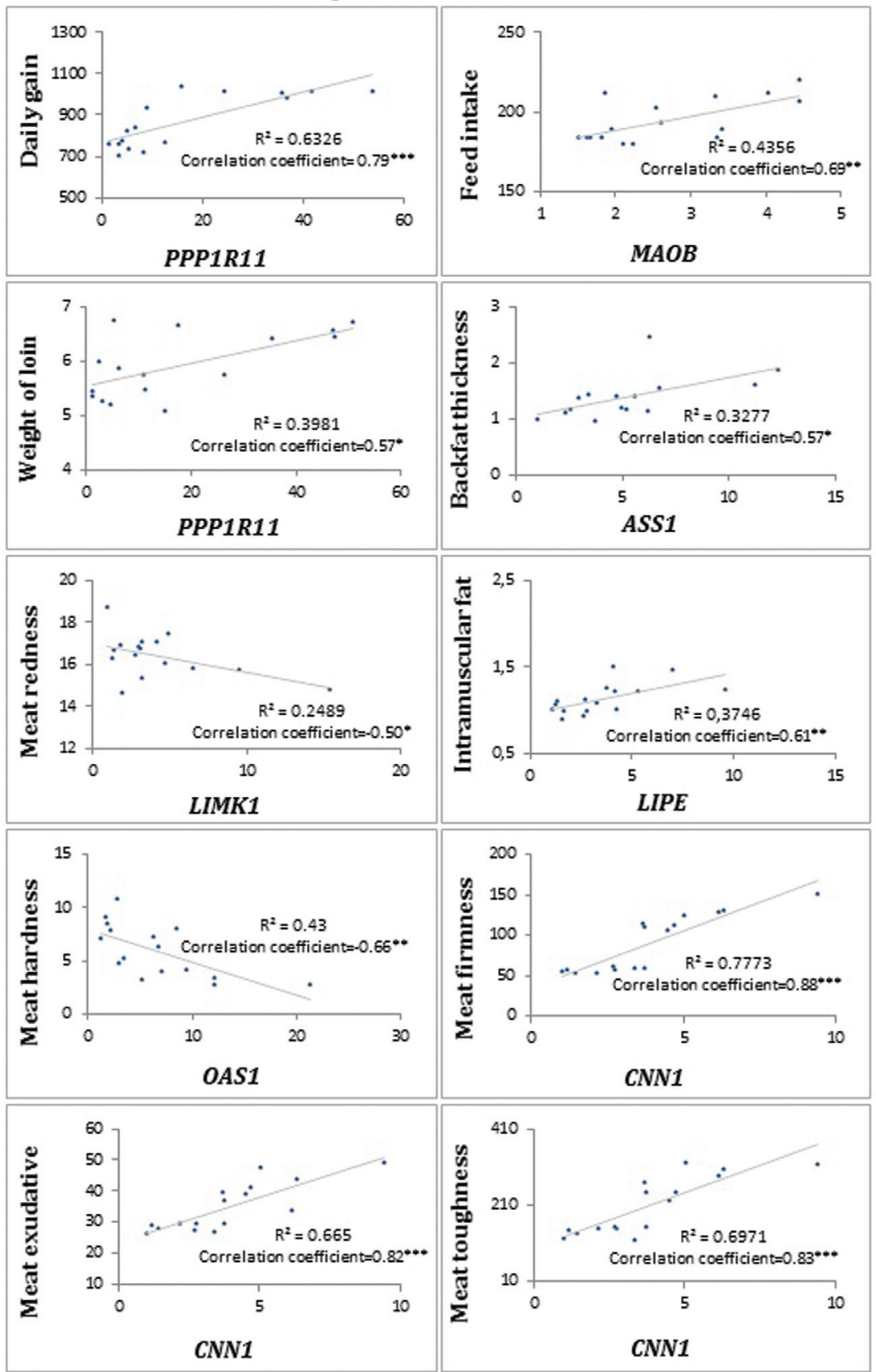

\section{Semimembranosus}
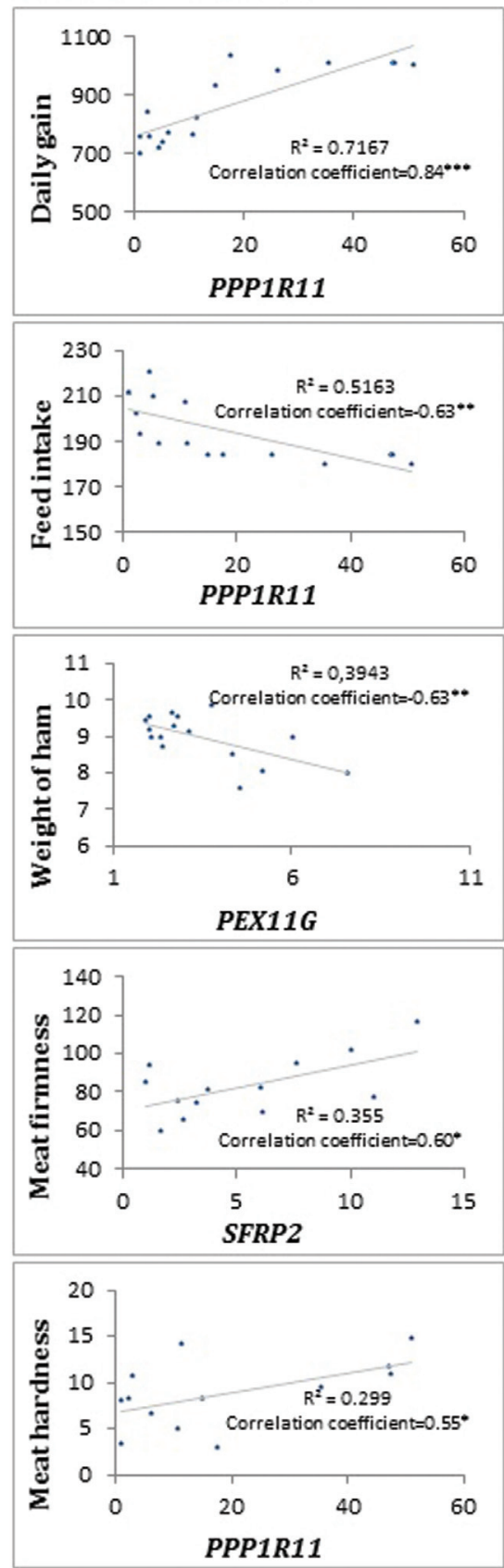

Figure 2 - Regression of genes with differential expression in longissimus dorsi and semimembranosus muscles against important pig traits. Gene expression is presented as normalized FPKM. Unit: daily gain $(\mathrm{g})$, feed intake $(\mathrm{kg})$, backfat thickness $(\mathrm{cm})$, weight of loin $(\mathrm{kg})$, weight of ham $(\mathrm{kg})$, meat redness $\left(A^{*}\right)$, intramuscular fat $(\%)$, meat firmness $(\mathrm{N} / \mathrm{mm} / \mathrm{s})$, meat hardness $(\mathrm{N} / \mathrm{mm} / \mathrm{s})$, meat exudation $(\mathrm{cm} 2) . * P \leq 0.05,{ }^{* *} P \leq 0.01,{ }^{* * *} P \leq 0.001$.

not exactly clear, but their increased expression in muscle tissue of pigs having high meat quality seems to be interesting. Therefore, they should be considered in further research.

The differentially expressed isoform analysis showed that in PUL muscles the seventh isoform of the SEPT6 gene was up-regulated. This SEPT6-007 isoform has a different length of the UTR region than the principal protein. SEPT6 encodes septin 6 that interacts with Rho, regulating the actin cytoskeleton in the GTPases pathway (Mostowy and Cossart, 2012). In addition, SEPT6 plays a role in cytokinesis, contributing to cell proliferation, and this could be associated with its influence on pork texture parameters.

\section{Genes overexpressed in Polish Landrace pigs}

These pig breed belong to the white pigs, having good growth traits, but its pork, as a consequence of breeding, has low quality. In the present study, the PL pigs presented 
extremely low meat quality, which allowed for a capture of genes associated with meat tenderness. Usually, the quality of PL pork is not so low (Ropka-Molik et al., 2016). Nevertheless, this parameter is not considered during selection, which could lead to additional deterioration of PL pork quality. Therefore, the aim of this research was to reveal candidate genes for pork quality traits.

During RNA-seq analysis, it was found that genes involved in actin filament building, collagen fibril organization and focal adhesion were overexpressed in PL muscles. Two up-regulated genes were found as playing a role in an interesting physiological pathway, such as Hippo signaling (PPP1R11, FRMD6). Hippo signaling regulates organ growth in Drosophila and vertebrates, controling the specification, differentiation and proliferation of cells. PPP1R11 encodes phosphatase 1 regulatory (inhibitor) subunit 11 (PPP1R11) that activates the YAP/TAZ complex, the main complex in Hippo signaling participating in apoptosis and cell proliferation (Halder and Johnson, 2011). In muscle, the mature fibers do not have the ability to proliferate, but the discovery of the myosatellite cells changed the view towards the emergence of new muscle fibers postnatally (Blaauw and Reggiani, 2014). The myosatellite cells have a multipotent character. They also can differentiate in the postnatal stage, thereby having an effect on myofibrillar network organization, contributing to the shaping of meat texture and water capacity (Bhat and Fayaz, 2011), and also growth traits. In the present correlation analysis, PPP1R11 expression in LD muscle was highly negatively associated with tenderness (highly positive correlation with firmness value $r=0.76$, corrected $P<0.01$ and toughness value $r=0.77$, corrected $P<0.01$ ). In addition, the expression level measured in both investigated muscles was positively related with daily gain (LD $r=0.80, \mathrm{~S} r=0.85$, corrected $P<0.01)$. It could be suggested that PPP1R11 plays some role in muscle fiber proliferation that occurs postnatally. Moreover, PPP1R11 is probably negatively associated with glucagon storage. Qiu et al. (2014) observed the overexpression of PPP1R11 in muscles of patients with diabetes mellitus type 1. Similarly Yang et al. (2000) identified increased PPPIR11 expression in skeletal muscles of insulin-sensitive Pima Indians. In turn, Kettunen et al. (2012) found that a single nucleotide polymorphism in PPP1R11 was associated with VLDL particle concentration in plasma of Finnish cohorts. On the other hand, the present correlation analysis showed a highly significant positive association between PPP1R11 expression in LD muscle and meat exudation measured also in longissimus dorsi ( $r=0.82$, corrected $P<0.01$ ). Our observation confirmed the previous studies that reported that water loss was positively correlated with IIb type fibers and negatively with I and IIa type fibers (Ryu and Kim, 2005; Wojtysiak and Poltowicz, 2014) showing a much higher percentage of IIb fiber in the PL skeletal muscles compared to the PUL breed. In view of the above evidence, the PPPIR11 gene is of interest in many contexts, both in its involvement in proliferation processes, glucagon storage, and influence on meat texture. Therefore, PPPIR11 should be widely investigated when searching for genetic markers for meat quality.

A highly significant correlation was also identified for CNN1 expression in longissimus dorsi. Increased CNN1 expression was positive associated with daily gain $(r=0.68$, corrected $P<0.05)$, water exudation ( $r=0.82$, corrected $P<0.01$ ), and negatively with tenderness (firmness $r=0.81$, corrected $P<0.01$, toughness $r=0.83$, corrected $P<0.01$ ). CNN1 encodes Calponin 1, which is a thin filamentassociated protein contributing to the modulation and regulation of smooth muscle contraction. Calponin 1 is capable of binding to actin, calmodulin, troponin $\mathrm{C}$ and tropomyosin. The interaction with actin inhibits actomyosin Mg-ATPase activity (Samaha et al., 1996). The CNN1 gene should be further analyzed in the context of effect on pork quality and growth traits.

On the other hand, in skeletal muscle of PL pigs, genes involved in calcium ion binding ( $P V A L B, C I B 2$, $P C D H 17$ and $C D H 11)$ were overexpressed. $\mathrm{Ca}^{2+}$ ions play a key role in the quality of pork through determining calpain activity (Lian et al., 2013), which is important in the tenderization process. CIB2 encodes calcium and integrin binding family member 2 protein (CIB2) that binds a novel integrin, $\alpha 7 \mathrm{~B} \beta 1 \mathrm{D}$. The absence of this integrin in muscle tissue results in myopathy, both in mice and humans (Häger et al., 2008). In turn, the protein encoded by $P V A L B$ is involved in the relaxation of muscle by rapidly sequestering calcium from the sarcoplasm of the cell (Mutryn et al., 2015). In the present study, a high correlation was observed between $P V A L B$ expression and meat texture parameters (firmness $r=0.71$, corrected $P<0.05$, toughness $r=0.68$ corrected $P<0.05)$ in LD muscle, which could be associated with its role in the calcium efflux process. In turn, the cadherins PCDH17 and CDH11 promote the fusion of mononuclear myoblast cells into polynuclear myotubes, which is one of the essential steps in myogenesis (Waibler and Starzinski-Powitz, 2002). Thus, these genes could influence pork texture parameters by determining muscle fiber development.

\section{Conclusions}

The study presents a gene cluster ( $P P P 1 R 11, S F R P 2$, CIB2, PVALB, UCHL1 and CNN1) that is probably associated with meat quality via regulating cell proliferation and differentiation, and calcium binding in muscles. Moreover, we propose a number of genes as candidates for fat content in pigs ( $L I P E, L X R A, H P)$, which were previously investigated in terms of human obesity. These candidate genes should be analyzed in future association studies, aiming at identifying genetic markers. 


\section{Acknowledgments}

This study was supported by Research Project No. 2013/09/D/NZ9/02452 founded by the National Science Centre in Poland.

\section{References}

Baez-Duarte BG, Zamora-Ginez I, Mendoza-Carrera F, RuizVivanco G, Torres-Rasgado E, Gonzalez-Mejia M and Perez-Fuentes R (2012) Serum levels of glutathione peroxidase 3 in overweight and obese subjects from central Mexico. Arch Med Res 43:541-547.

Bhat ZF and Fayaz H (2011) Prospectus of cultured meat - Advancing meat alternatives. J Food Sci Technol 48:125-140.

Blaauw B and Reggiani C (2014) The role of satellite cells in muscle hypertrophy. J Muscle Res Cell Motil 35:3-10.

Benes V, Blake J and Doyle K (2011) Ribo-Zero Gold Kit: Improved RNA-seq results after removal of cytoplasmic and mitochondrial ribosomal RNA. Nat Methods 8:11.

Chiellini C, Santini F, Marsili A, Berti P, Bertacca A, Pelosini C, Scartabelli G, Pardini E, López-Soriano J, Centoni R, et al. (2004) Serum haptoglobin: A novel marker of adiposity in humans. J Clin Endocrinol Metab 89:2678-2683.

Chimonyo M, Dzama K and Mapiye C (2010) Growth performance and carcass characteristics of indigenous Mukota pigs of Zimbabwe. Trop Anim Health Prod 42:1001-1007.

Christoffolete MA, Doleschall M, Egri P, Liposits Z, Zavacki AM, Bianco AC and Gereben B (2010) Regulation of thyroid hormone activation via the liver X-receptor/retinoid X-receptor pathway. J Endocrinol 205:179-186.

Corominas J, Ramayo-Caldas Y, Puig-Oliveras A, Estellé J, Castelló A, Alves E and Folch JM (2013) Analysis of porcine adipose tissue transcriptome reveals differences in de novo fatty acid synthesis in pigs with divergent muscle fatty acid composition. BMC Genomics 14:843.

Desai PP, Bunker CH, Ukoli FA and Kamboh MI (2002) Genetic variation in the apolipoprotein $\mathrm{D}$ gene among African blacks and its significance in lipid metabolism. Atherosclerosis 163:329-338.

Esteve-Codina A, Kofler R, Palmieri N, Bussotti G, Notredame C and Pérez-Enciso M (2011) Exploring the gonad transcriptome of two extreme male pigs with RNA-seq. BMC Genomics 12:1.

Fan B, Tang ZL, Xu SP, Liu B, Peng ZZ and Li K (2006) Germplasm characteristics and conservation of Tongcheng pig: A case study for preservation and utilization of Chinese indigenous pig breeds. Anim Genet Res 39:51-63.

Grau R and Hamm (1953) Eine einfache Metode zur Bestimmung der Wasserbindung in Muskel. Naturwissenschaften 40:29.

Halder G and Johnson RL (2011) Hippo signaling: Growth control and beyond. Development 138:9-22.

Hardcastle TJ and Kelly KA (2010) baySeq: empirical Bayesian methods for identifying differential expression in sequence count data. BMC Bioinformatics 11:422.

Hardwick JP, Osei-Hyiaman D, Wiland H, Abdelmegeed MA and Song B-J (2010) PPAR/RXR regulation of fatty acid metabolism and fatty acid hydroxylase (CYP4) isozymes: Implications for prevention of lipotoxicity in fatty liver disease. PPAR Res 2009:952734.
Hayes BJ, Bowman PJ, Chamberlain AJ and Goddard ME (2009) Genomic selection in dairy cattle: Progress and challenges. J Dairy Sci 92:433-443.

Häger M, Bigotti MG, Meszaros R, Carmignac V, Holmberg J, Allamand V and Durbeej M (2008) Cib2 binds integrin $\alpha 7 \mathrm{~B} \beta 1 \mathrm{D}$ and is reduced in laminin $\alpha 2$ chain-deficient muscular dystrophy. J Biol Chem 283:24760-24769.

Holm C, Belfrage P, Østerlund T, Davis RC, Schotz MC and Langin D (1994) Hormone-sensitive lipase: Structure, function, evolution and overproduction in insect cells using the baculovirus expression system. Protein Eng 7:537-541.

Hsu SH, Lai MC, Er TK, Yang SN, Hung CH, Tsai HH and Jong YJ (2010) Ubiquitin carboxyl-terminal hydrolase L1 (UCHL1) regulates the level of SMN expression through ubiquitination in primary spinal muscular atrophy fibroblasts. Clin Chim Acta 411:1920-1928.

Huff-Lonergan E and Lonergan SM (2005) Mechanisms of water-holding capacity of meat: The role of postmortem biochemical and structural changes. Meat Sci 71:194-204.

Huff-Lonergan E, Zhang W and Lonergan SM (2010) Biochemistry of post mortem muscle -lesson of mechanism of meat tenderization. Meat Sci 86:184-195.

Hurd PJ and Nelson CJ (2009) Advantages of next-generation sequencing versus the microarray in epigenetic research. Brief Funct Genomics 8:174-183.

Kasprzyk A, Tyra M and Babicz M (2015) Fatty acid profile of pork from a local and a commercial breed. Arch Anim Breed 58:379-385.

Kettunen J, Tukiainen T, Sarin AP, Ortega-Alonso A, Tikkanen E, Lyytikäinen LP, Kangas AJ, Soininen P, Würtz P, Silander K, et al. (2012) Genome-wide association study identifies multiple loci influencing human serum metabolite levels. Nat Genet 44:269-276.

Love MI, Huber W and Anders S (2014) Moderated estimation of fold change and dispersion for RNA-seq data with DESeq2. Genome Biol 15:550.

Lian T, Wang L and Liu Y (2013) A new insight into the role of calpains in post-mortem meat tenderization in domestic animals: A review. Asian-Australas J Anim Sci 26:443.

Miller MF, Carr MF, Ramsey CB, Crockett KL and Hoover LC (2001) Consumer thresholds for establishing the value of beef tenderness. J Anim Sci 79:3062-3068.

Martínez-Montes AM, Fernández A, Pére-Montarelo D, Alves E, Benítez RM, Nuñez Y and Fernández AI (2016) Using RNA-Seq SNP data to reveal potential causal mutations related to pig production traits and RNA editing. Anim Genet 48:151-165.

Mostowy S and Cossart P (2012) Septins: the fourth component of the cytoskeleton. Nat Rev Mol Cell Biol 13:183-194.

Mutryn MF, Brannick EM, Fu W, Lee WR and Abasht B (2015) Characterization of a novel chicken muscle disorder through differential gene expression and pathway analysis using RNA-sequencing. BMC Genomics 16:1.

Pang WJ, Bai L and Yang G (2006) Relationship among H-FABP gene polymorphism, intramuscular fat content, and adipocyte lipid droplet content in main pig breeds with different genotypes in Western China. Yi Chuan Xue Bao 33:515524.

Piórkowska K, Zukowski K, Nowak J, Poltowicz K, Ropka-Molik K and Gurgul A (2016) Genome-wide RNA-Seq analysis of 
breast muscles of two broiler chicken groups differing in shear force. Anim Genet 47:68-80.

Ponsuksili S, Murani E, Brand B, Schwerin M and Wimmers K (2011) Integrating expression profiling and whole genome association for dissection of fat traits in a porcine model. J Lipid Res 52:668-678.

Olkiewicz M (2009) Zmiany konsystencji szynek surowych dojrzewajacych w czasie procesu produkcji na przykladzie szynek z wybranych polskich ras. Acta Agroph 14:691-700.

Qiu Y-H, Deng F-Y, Li M-J and Lei S-F (2014) Identification of novel risk genes associated with type 1 diabetes mellitus using a genome wide gene-based association analysis. J Diabetes Investig 5:649-656.

Robinson MD, Oshlack A (2010) A scaling normalization method for differential expression analysis of RNA-seq data. Genome Biol 11:R25.

Ropka-Molik K, Bereta A, Tyra M, Rózycki M, Piórkowska K, Szyndler-Nedza M and Szmatola T (2014a) Association of calpastatin gene polymorphisms and meat quality traits in pig. Meat Sci 97:143-150.

Ropka-Molik K, Zukowski K, Eckert R, Gurgul A, Piórkowska K and Oczkowicz M (2014b) Comprehensive analysis of the whole transcriptomes from two different pig breeds using RNA-Seq method. Anim Gen 45:674684.

Ropka-Molik K, Podstawski P, Piórkowska K and Tyra M (2016) Association of gene coding for microtonal triglyceride transfer protein (MTP) and meat texture characteristic in pig. Ann Anim Sci 16:721-729.

Ryu YC and Kim BC (2005) The relationship between muscle fiber characteristics, postmortem metabolic rate, and meat quality of pig longissimus dorsi muscle. Meat Sci 71:351357.

Samaha FF, Ip HS, Morrisey EE, Seltzer J, Tang Z, Solway J and Parmacek MS (1996) Developmental pattern of expression and genomic organization of the calponin-h1 gene a contractile smooth muscle cell marker. J Biol Chem 271:395-403.

Spurlock ME and Gabler N (2008) The development of porcine models of obesity and the metabolic syndrome. J Nutr 138:397-402.

Szyndler-Nedza M, Tyra M, Blicharski T and Piórkowska K (2010) Effect of mutation in MC4R gene on carcass quality in Pulawska pig included in conservation breeding programme. Anim Sci Pap Rep 28:37-45.

Takahashi K, Avissar N, Whitin J and Cohen H (1987) Purification and characterization of human plasma glutathione peroxidase: A selenoglycoprotein distinct from the known cellular enzyme. Arch Biochem Biophys, 256:677-686.

Tyra M and Zak G (2013) Analysis of the possibility of improving the indicators of pork quality through selection with particu- lar consideration of intramuscular fat (MF) content. Ann Anim Sci 13:33-44.

Tyra M, Ropka-Molik K, Terman A, Piórkowska K, Oczkowicz M and Bereta A (2013) Association between subcutaneous and intramuscular fat content in porcine ham and loin depending on age, breed and FABP3 and LEPR genes transcript abundance. Mol Biol Rep 40:2301-2308.

Waibler Z and Starzinski-Powitz A (2002) Cadherins in skeletal muscle development. In: Brand-Saberi B (ed) Vertebrate Myogenesis. Results and Problems in Cell Differentiation, Vol 38. Springer, Berlin, pp 187-198.

Wojtysiak D and Poltowicz K (2014) Carcass quality, physicochemical parameters, muscle fibre traits and myosin heavy chain composition of $\mathrm{m}$. longissimus lumborum from Pulawska and Polish Large White pigs. Meat Sci 97:395403.

Yang X, Pratley R, Tokraks S, Bogardus C and Permana PA (2000) Microarray profiling of skeletal muscle tissues from equally obese, non-diabetic insulin-sensitive and insulinresistant Pima Indians. Diabetologia 45:1584-1593.

Yu M, Geiger B, Deeb N and Rothschild MF (2006) Liver X receptor alpha and beta genes have the potential role on loin lean and fat content in pigs. J Anim Breed Gen 123:81-88.

Zhang CY, Wang Z, Bruce HL, Janz J, Goddard E, Moore S and Plastow GS (2014) Associations between single nucleotide polymorphisms in 33 candidate genes and meat quality traits in commercial pigs. Anim Genet 45:508516.

Xue W, Wang W, Jin B, Zhang X and Xu X (2015) Association of the ADRB3, FABP3, LIPE, and LPL gene polymorphisms with pig intramuscular fat content and fatty acid composition. Czech J Anim Sci 60:60-66.

\section{Supplementary material}

The following online material is available for this article: Table S1 - Overall statistics and read annotations obtained for each library.

Table S2 - Primer and TaqMan probes used in validation. Table S3 - Genes differentially expressed in semimembranosus muscle of Polish Landrace pigs.

Table S4 - Pearson correlation coefficient for DEGs in longissimus dorsi and pig production traits.

Table S5 - Correlation coefficient for DEGs in semimembranosus and pig production traits.

\section{Associate Editor: Alexandre Rodrigues Caetano}

License information: This is an open-access article distributed under the terms of the Creative Commons Attribution License (type CC-BY), which permits unrestricted use, distribution and reproduction in any medium, provided the original article is properly cited. 